\title{
RursuSpicae
}

Transmission, réception et réécriture de textes, de I'Antiquité au Moyen Âge

$2 \mid 2019$

Le Physiologus. Manuscrits anciens et tradition médiévale

\section{El basilisco, del bestiario al libro de caballerías castellano. El caso del Palmerín de Olivia (Salamanca, Juan de Porras, 1511)}

The Basilisk, from the Bestiary to the Spanish Book of Chivalries. The Case of Palmerín de Olivia (Salamanca, Juan de Porras, 1511)

Le basilic, du bestiaire au livre de chevalerie castillan. Autour de Palmerín de Olivia (Salamanca, Juan de Porras, 1511)

\section{Lucía Orsanic}

\section{OpenEdition}

\section{Journals}

\section{Edición electrónica}

URL: http://journals.openedition.org/rursuspicae/1188

DOI: $10.4000 /$ rursuspicae. 1188

ISSN: 2557-8839

Editor.

Université Nice-Sophia Antipolis, IRHT - Institut de recherche et d'histoire des textes

\section{Referencia electrónica}

Lucía Orsanic, «El basilisco, del bestiario al libro de caballerías castellano. El caso del Palmerín de Olivia (Salamanca, Juan de Porras, 1511) », RursuSpicae [En ligne], 2 | 2019, mis en ligne le 20 décembre 2019, consulté le 29 mars 2021. URL : http://journals.openedition.org/rursuspicae/1188 ; DOI : https://doi.org/10.4000/rursuspicae. 1188

Este documento fue generado automáticamente el 29 marzo 2021.

RursuSpicae 


\title{
El basilisco, del bestiario al libro de caballerías castellano. El caso del Palmerín de Olivia (Salamanca, Juan de Porras, 1511)
}

\author{
The Basilisk, from the Bestiary to the Spanish Book of Chivalries. The Case of \\ Palmerín de Olivia (Salamanca, Juan de Porras, 1511) \\ Le basilic, du bestiaire au livre de chevalerie castillan. Autour de Palmerín de \\ Olivia (Salamanca, Juan de Porras, 1511)
}

Lucía Orsanic

\section{El Fisiólogo, génesis y pervivencia de lo monstruoso}

1 Desde la noche de los tiempos, el monstruo ha ocupado un lugar relevante en las sociedades humanas, vinculado con los miedos, con los temores, con las proyecciones que en cada contexto histórico representaron amenazas hacia la mismidad, desde una esfera alterna. Los monstruos han sabido metamorfosearse a lo largo de la historia pero su permanencia, con mayores o menores variantes, nos habla de su papel central en los relatos; de los cuales podemos hacer lecturas de índole antropológica, teológica, filosófica, legal, psicológica, filológica, plástica. El monstruo es, por definición, un objeto de estudio que puede abordarse desde múltiples perspectivas que enriquecen nuestra mirada del sujeto teratológico. En esta línea, la estética de lo monstruoso nos permite poner atención a una serie de rasgos que, en los años 90, Victoria Cirlot sistematizó en: la deformidad, la hibridez, el exceso y la exuberancia. A lo que podemos añadir dos elementos. De modo general, consideramos todo aquello que se escapa de la norma establecida, en un contexto determinado; de modo específico, podemos precisar dos procesos narratológicos para la construcción del imaginario de la teratología, la imitación y la variación sobre una base genológica compleja, discursiva e iconográfica. 
En este sentido, hay que destacar el papel de los bestiarios como fuentes ineludibles para el estudio de lo monstruoso. La definición propuesta por Nilda Guglielmi, "una obra seudocientífica moralizante, sobre animales existentes y fabulosos" (GUGLIELMI, 1971: 7), fue objetada por Ignacio Malaxecheverría; quien puso en jaque los calificativos seudocientífica, como expresión que remite a la cosmovisión del hombre moderno antes que medieval; moralizante, porque dejaría de lado otros bestiarios -como de Richard de Fournival-y existentes y fabulosos, pues para la época todos los animales mencionados son considerados como parte de la realidad medieval. Asimismo, Malaxecheverría sostiene que no hay un único bestiario sino una pluralidad con características diversas, aunque todos procedan de un hipotético Physiologus, que puedo haberse redactado en Alejandría entre los siglos II y $\mathrm{V}$ de nuestra era, pero que no conservamos (MALAXECHEVERRíA, 1986: 207). Por nuestra parte, entendemos el bestiario como una obra construida sobre una base discursiva e iconográfica -donde ambas resultan complementarias y reforzadoras de sentido- que presenta las características de ciertos animales seleccionados, de acuerdo con su valor simbólico, en función de la doctrina cristiana. Ciertamente los bestiarios zoológicos no son los únicos que existen pero, atendiendo a los límites de nuestra investigación, optamos por circunscribirnos a ellos, dado que el basilisco constituye el objeto específico de este trabajo.

El término Fisiólogo no se limita a su acepción naturalista dentro del cristianismo primitivo en el que se gestó la obra, sino que también se refiere a "aquella persona que trata de someter el mundo natural a una interpretación trascendente, moral y/o doctrinal, con el fin de ilustrar y hacer fácilmente comprensibles determinados preceptos y dogmas de la religión. Se trata [...] de un exégeta de la naturaleza según los cánones de la fe cristiana" (GARCíA ARRANZ, 2014: 74). Precisamente en esta exégesis vinculada con los animales hace hincapié Arnaud Zucker, como una de las características propias de la zoología cristiana:

La 'zoologie chrétienne' est essentiellement générée par l'activité exégétique, et elle s'exprime principalement dans les commentaires à la Genèse ou aux six jours de la création (le genre homilétique de l'Hexaéméron), et les commentaires des textes poétiques de l'Ancien Testament ainsi que des images du Nouveau. Le postulat d'une symbolicité essentielle des créatures animales découle ainsi de ce contexte de représentation, où l'animal est absorbé dans le processus global de décodage et de reformulation des Ecritures. Et c'est naturellement qu'elles sont investies d'une function de témoignage dans un système où les signes convergent vers un horizon moral et théologique. L'attention presque exclusive que portent les textes chrétiens anciens (épistolaires, apologétiques, homilétiques, exégétiques) au sens figuré ou allégorique des animaux, permet de situer et de comprendre le projet du texte connu sous le nom de Physiologos, ouvrage simple et populaire qui fait de la vocation spirituelle du signe animal un principe de composition, en offrant une série de diptyques présentant comme les faces réelles d'une même médaille la description d'une nature animale, d'une part, et sa valeur spirituelle, d'autre part. [...] Les animaux [...] constituent des candidats rêvés pour le rôle de mimes et de figures prototypiques d'un monde dont tous les éléments portent le sens entier de la création. (ZUCKER, 2007: 1-2).

El Fisiólogo fue una obra muy popular, que alcanzó rápidamente un éxito notable y una gran difusión, como se atestigua a raíz de las múltiples traducciones al árabe, al siríaco, al armenio, al etíope, entre otras lenguas; cuyos manuscritos han llegado hasta nuestros días. En la Europa occidental, se difundió a partir de las traducciones latinas que se habrían iniciado alrededor de los siglos IV y V, aunque son del siglo VIII las que se conservan hoy como las más antiguas. Dichas versiones fueron evolucionando, 
principalmente a raíz de la añadidura de capítulos y contenidos nuevos durante el Medioevo, lo que originó distintas familias de manuscritos; entre los textos que fueron engrosando la versión primitiva del Fisiólogo se hallan obras de autores cristianos, como el Hexaemeron de Ambrosio de Milán, las Etimologías de Isidoro de Sevilla y el De universo de Rabano Mauro. El Fisiólogo se organiza en torno a una selección de animales y monstruos -alrededor de cincuenta en los textos más antiguos-, cada uno de ellos está encabezado por una cita veterotestamentaria, seguido de la descripción zoológica/ teratológica alegorizada en función de la doctrina cristiana, y de una nueva cita bíblica a modo de clausura. La autoridad para exponer cada uno de los animales/monstruos ejemplares se desprende, por un lado, del anónimo fisiólogo -en el sentido de hermeneuta de la naturaleza que antes subrayamos- y por otro lado, de la Biblia como auctoritas medieval por excelencia (GARCíA ARRANZ, 2014: 75-77). De este modo, los animales/monstruos eran identificados con Cristo o con el demonio, con el hombre bueno o con el pecador; de acuerdo con sus hábitos biológicos, su alimentación, su hábitat, su forma de aparearse y su aspecto físico.

Cabe señalar la influencia posterior del Fisiólogo, no solo en el espectro de los bestiarios subsiguientes durante el Medioevo, sino también en otros tipos discursivos. García Arranz destaca su importancia "en las colecciones de exempla, en detalles marginales de la iluminación de manuscritos o en ciertos programas icónicos de ornamentación arquitectónica" (GARCÍA ARRANZ, 2014: 77-78) pero también queremos mencionar los libros de viajes, los libros de caballerías, las crónicas del Nuevo Mundo, las relaciones de sucesos, las misceláneas, los libros de emblemas y los tratados de monstruos. Aunque el tratamiento de los seres teratológicos varía en cada uno de ellos, de acuerdo con los supuestos de cada tipo discursivo, la imagen del monstruo es una constante, atenuada por los valores ideológicos, culturales y de poder a los que se suscribe cada uno de los textos.

\section{La hibridez como dispositivo narratológico de la construcción monstruosa}

5 Muchos de los monstruos del Fisiólogo y otros bestiarios posteriores son de carácter híbrido. Cuando hablamos de hibridación, nos referimos a la mezcla de dos o más seres cuya naturaleza puede o no ser la misma. Así, es posible tener una hibridación que se limite al reino animal (cabeza de A, cuerpo de B, alas de C, patas de D, cola de E, etcétera) pero también existe la posibilidad de entremezclar reinos diversos y componer un ser monstruoso que combine elementos vegetales, animales y humanos (hombre-vegetal, como las mandrágoras; hombre-animal como los tritones; vegetal-animal, como el cordero vegetal). Dentro de las cuantiosas posibilidades combinatorias, puede hacerse una clasificación inicial entre los híbridos conocidos/monstruos viejos y los híbridos imaginarios/monstruos nuevos (MARÍN PINA, 1993 y GLOCKNER, 1994); mientras que los primeros encarnan seres teratológicos cristalizados por los bestiarios y las historias naturales, que no precisan una descripción detallada para visualizar su morfología, los segundos se corresponden con la creación original de un autor en un libro determinado. Por supuesto, cabe replantearse la idea de un monstruo "original", dado que en realidad todos los monstruos son el resultado de la historia teratológica y se desprenden de una larga tradición, sobre la que es posible ejercer más o menos variantes pero cuyo arquetipo es el mismo. 
6 En los textos antiguos referidos a la ophiologia (del griego, ophis 'serpens' + logos 'scientia'), el término 'basiliscos' hace referencia a un tipo de serpiente que, andando el tiempo, cobraría rasgos híbridos para decantar en el arquetipo gallo-serpiente. Analizaremos primero cada uno de estos animales individualmente, para arribar al estudio del basilisco tradicional que presentan los bestiarios. Luego, veremos la imagen alternativa de este monstruo que nos ofrece el Palmerín de Olivia y explicaremos las razones de esta transformación.

\section{La serpiente}

7 El Génesis, auctoritas por excelencia para el hombre medieval, es la primera fuente cristiana que condena a la serpiente, seguido de todas las lecturas de los textos patrísticos, reforzadores de la misma idea demoníaca que posteriormente decanta en los discursos literarios. El célebre pasaje reza lo que sigue: "Entonces Yavé Dios dijo a la serpiente: «Por haber hecho esto, maldita seas entre todos los animales y entre todas las bestias del campo. Te arrastrarás sobre tu vientre y comerás del polvo de la tierra todos los días de tu vida. Yo pongo enemistad entre ti y la mujer, entre tu linaje y el suyo; él te aplastará la cabeza mientras tú te abalances a su calcañal»" (Gn. 3, 14-16) y constituye la base para el arquetipo de la serpiente edénica. Precisamente, en el contexto cristiano propio de los libros de caballerías ${ }^{1}$, entendemos la importancia de la primera aventura de Palmerín con la sierpe, isomorfo del dragón, que funciona como su iniciación caballeresca y máxime representación demoníaca (PO, XVII-XVIII: 40-43).

Es notable que la clasificación de las serpientes que hacen los bestiarios y las historias naturales sea bastante más minuciosa que cualquiera de los otros animales seleccionados. Eso nos habla de la importancia que este animal, devenido en monstruo (dragón, reptil o cualquiera de sus isomorfos), ha tenido en las sociedades desde tiempos muy antiguos. Así, por ejemplo, encontramos la anfisbena (Amphisbena), que "tiene dos cabezas. Una cabeza se halla en el lugar adecuado, y la otra en la cola. Con una cabeza sujetando a la otra, puede rodar en cualquier dirección, como un aro. Esta es la única serpiente que aguanta bien el frío, y es la primera que sale de la hibernación" (Cambridge, 176-177, apud MALAEXCHEVERRÍA, 1986: 183). Este tipo representa el arquetipo de la serpiente uróboros, vinculada con el infinito y el andrógino. Otra cuestión relacionada con los ojos brillantes de la anfisbena y la petrificación como consecuencia de la mirada es el llamado mal de ojo, ya que "el miedo a la mirada fija es universal. [...]. Todas las razas humanas comparten la idea de que la mirada humana penetra o traspasa, con lo que esta creencia afirma la premisa fundamental de la superstición del mal de ojo: que la mirada lesiona o altera la realidad" (SIEBERS, 1993: 73-74). Como consecuencia, el ojo se convierte en un órgano poderoso con la capacidad de dominar y dirigir los acontecimientos a su alrededor, a partir de la mirada; un rasgo serpentino crucial para definir al basilisco de las fuentes tradicionales. Otro ejemplar destacado en el mundo serpentino es el áspid, que

quema la hierba que se encuentra cerca de su nido. Al extenderse la sequedad de su aliento, quema toda la tierra en un círculo de tres pies, y ningún ser vivo puede acercarse a menos de siete pies; y si alguien, hombre o bestia, entra dentro de este radio, con seguridad ha de morir. [...] Cuando el encantador se aproxima, el áspid yace muy cerca mirándole y se tapa los oídos para no oír la voz del encantador; pues si oye su voz muere en seguida. [...] Y el encantador que la ha sometido se convierte en su amo, y obtiene de ella lo que quiera. Del mismo modo estuvieron los judíos, en 
su tiempo, aferrados al error (...). Y dijo el profeta David: «Tienen veneno semejante al veneno de las serpientes/son áspides sordos, que cierran sus oídos. Para no oír la voz del encantador,/por hábil que este sea» (Salmo 58, 5-6). Con razón fueron llamados los judíos áspid que tapa sus oídos, ya que no oyen la voz del encantador, el esposo, ni la voz de las Sagradas Escrituras. También al demonio se le llama áspid; el calor abrasador es el poder del mal; el suelo es el infierno y sus tormentos. ¿Quién es el encantador? Es Cristo" (Phys. griego: Carlill, 234-235, apud MALAXECHEVERRíA, 1986: 183-184).

9 Esta cita evidencia igualmente características del basilisco, cuando se refiere al aliento y a la capacidad de quemar los campos. Y sobre la víbora, dice el Fisiólogo que "Nuestro Salvador, asimiló los fariseos a las víboras: así como los de esta raza matan a sus padres y a sus madres, así también el pueblo judío, que no tiene Dios, mató a Jesucristo, su padre, y a Jerusalén, su madre terrenal" (Fisiólogo, XII: 48).

10 La crítica ha hecho hincapié en la dualidad simbólica de los animales de forma recurrente, del mismo modo que subrayado la complementariedad de los polos positivos y negativos de la vastedad zoomorfa/teratológica. Por eso, como bien subraya Ignacio Malaxecheverría:

Lo importante no es que el dragón sea benéfico en China y nefasto en los textos medievales, sino que culturas tan alejadas hayan centrado su atención en él, lo que demuestra que se trata de un animal arquetípico, cuya valoración es diversa; otro tanto podría decirse del unicornio, del cocodrilo o de la pantera. Lo esencial reside en el hecho de que determinadas bestias, sacralizadas en África o Asia, hayan inquietado o atraído en Europa occidental. A falta de "puentes culturales" demostrables, tales vinculaciones indican al menos un común interés (MALAXECHEVERRÍA, 1986: 230).

11 Como consecuencia, el contexto en el que aparece el animal que se estudia es de vital importancia, del mismo modo que la acción que este realiza; de lo contrario, sería muy sencillo caer en un reduccionismo hermenéutico². En la misma línea, Arnaud Zucker destaca la importancia de analizar los animales en situación: “Le symbole est motivé par un contexte et déterminé par une visée [...]. L'unité de base de la symbolique n'est pas un objet, ou un signe, mais une phrase ou un épisode, qui associe une figure à une ou plusieurs actions qui la situent" (ZUCKER, 2007: 5). Así, los valores que se atribuyen a los animales en la tradición de los bestiarios y los textos subsiguientes adquieren una significación cristiana de acuerdo con la situación narrativa y no en función de su especie zoológica, los animales ofrecen diversas y numerosas situaciones en las que actúan, desde donde se desprenden las interpretaciones polivalentes que pueden hacerse de ellos.

\section{El gallo}

12 En el mundo antiguo, el gallo era considerado como un ave noble, especialmente por su cualidad de vigilante, de ahí, que fuera tenido por el profeta que "anuncia en el seno mismo de la más oscura noche el advenimiento cierto de la luz del sol" (CHARBONNEAULASSAY, 1997: II, 629) y se utilizara para la adivinación. A propósito, Isidoro de Sevilla distingue entre las aves oscines (las que vaticinan por su voz o canto), las aves alites (las que lo hacen por su vuelo) y las aves comunes (las que no poseen cualidades excepcionales y se remiten pura y exclusivamente a su naturaleza zoomórfica), de acuerdo con la forma en que sean o no capaces de llevar a cabo los augurios. En el caso del gallo, afirma que es 
llamado así por castración, pues entre las demás aves es la única que sufre esta operación. Los antiguos lo llamaban gallos castrados; gallina viene de gallo, como leona de león y dragona de dragón. Se dice que los miembros del gallo se consumen si se mezclan con oro licuescente" (ISIDORO DE SEVILLA, Etimologías, XII, vii: 312).

13 Esta es la única referencia que encontramos sobre dicho animal en las Etimologías. Queremos detenernos en tres puntos. Primero, la imagen de la castración. El gallo castrado es considerado in extenso por Sebastián de Covarrubias, quien afirma que siempre resultan mejores los gallos criados sin gallinas que los capados pero que lo más frecuente es realizar la operación cuando son todavía pollos. El autor del Tesoro trae a colación a Plinio, quien describe minuciosamente el procedimiento para capar los gallos ${ }^{3}$, y explica su origen, a raíz de la promulgación de una ley decretada por los censores romanos "de que ninguno comiese gallina por moderar los gastos, y dieron en castrar los gallos y cebarlos con sopas de leche"; finalmente advierte que el nombre de "gallo capado" fue aplicado por poetas como Marcial, por ejemplo, quien de modo satírico se sirvió del término para referirse a ciertos sacerdotes castrados voluntariamente (COVARRUBIAS, Tesoro de la lengua castellana o española: 575-576). Segundo, Isidoro extrae los nombres femeninos de los masculinos: "gallina viene de gallo, como leona de león, como dragona de dragón". En cualquiera de los dos casos, el principio masculino es el punto de partida del término femenino para designar al ente que se nombra, así como también explica su generación desde un punto de vista biológico. Tercero, Isidoro menciona que los miembros del gallo "se consumen si me mezclan con oro licuescente", lo cual se asocia con cierto tipo de magia y hasta podría atribuirse a un proceso alquímico, si se tiene en cuenta la importancia del metal mencionado para la alquimia. Siguiendo esta lectura, se comprende que el gallo haya sido relacionado con modos de adivinación diferentes de los que se llevaban a cabo con otro tipo de aves. Una de las formas empleadas fue la alectriomancia, la adivinación a través del gallo degollado, que a menudo debía ser negro. Asimismo, el objeto más preciado era la llamada Piedra Alectoriana, que se encontraba en el pecho de los gallos, pero únicamente en los de combate. Precisamente, hablar de una piedra con poderes supremos vuelve nuestra atención a propósito de la alquimia ya mencionada, como así también de todo el género que constituyeron los lapidarios durante la Edad Media. En esta misma línea, se creía que la molleja del gallo castrado contenía otra piedra de carácter similar y maravilloso, que otorgaba la sabiduría y el discernimiento -a diferencia de la primera, cuyas virtudes eran más bien de arrojo, tales como el poder de decisión, la audacia y el vigor-. Esta segunda piedra se conoció durante el Medioevo como la Piedra de Capón o Caponeta (CHARBONNEAU-LASSAY, 1997: II, 628-632).

Si bien estas creencias mágicas no se extirparon totalmente, la Edad Media procuró neutralizarlas, de acuerdo con la fe cristiana. Dicho de otro modo, se llevó a cabo una reinterpretación de la magia que atribuyó al ámbito demoníaco todos los elementos del paganismo que no fueran compatibles con los dogmas cristianos. Tal como apunta Julio Caro Baroja: "Así, sin atender a grados ni matices, los antiguos dioses se vieron asimilados a los demonios, ni más ni menos: o al Diablo, abstrayendo y unificando más los conceptos. Lo que podía haber de pío y moral, de decoroso dentro de los cultos domésticos y públicos griegos y romanos, no fue tenido en cuenta" (CARO BAROJA, 1993: 65). El autor menciona una sentencia de Tertuliano, que resulta más que ilustrativa: “¿Quiénes no tienen que ganar con los cristianos? Los alcahuetes y otros agentes de la lujuria, los asesinos sicarios, los envenenadores, los magos, los arúspices, los adivinos (arioli) y los que se dan a la Astrología (mathematici)" (CARO BAROJA, 1993: 65). Todos los 
mencionados se colocan en el mismo nivel: la alcahueta -como la celebérrima Celestina de las letras hispánicas- pasa por el mismo tamiz que el asesino, sin contemplar las sutilezas de sus diversos "trabajos", ambos son igualmente condenados como agentes del demonio y por eso deben ser removidos de la sociedad a través del castigo ejemplar.

Al lado de las creencias que todavía guardan resabios mágicos, el gallo, como otros animales, se transforma en una imagen crística. El ave de la luz, el que anuncia el día, encarna también las figuras del padre, del jefe y del guía. La voz del gallo se diferencia de otras expresiones animales, incluso del canto de las aves: "Es la señal de alerta, es la voz del jefe o del padre atento, es el cuerno del triunfador que toca a los cuatro vientos, muy alto, su victoria y su alegría [...] [que ahuyenta] todas las malas potencias de las tinieblas, los genios nocturnos, las larvas, los vampiros, los lemures, los fantasmas y los espectros de todas las clases" (CHARBONNEAU-LASSAY, 1997: II, 634). Así, la voz del gallo o el galicinio representa la voz de Cristo, quien se dirige a las almas para convocarlas a la oración. Del mismo modo, el uso que los romanos hicieron del gallo como motivo de veleta, fue posteriormente cristianizado, al ser colocado en el punto más alto de las iglesias, en una doble representación del estar alerta del buen cristiano y de Cristo que, desde la cima de su Iglesia, protege a sus hijos y permanece firme aún en los vientos y tormentas (CHARBONNEAU-LASSAY, 1997: II, 628-639).

16 Testimonio de su importancia en el cristianismo, es la aparición de la figura del gallo en el marco del texto bíblico. A propósito de la Pasión de Jesucristo, los cuatro relatos evangélicos mencionan el popular galicinio, tras la negación de Pedro (Mt. 26, 69-75; Mc. 14, 66-72; Lc. 22, 55-62 y Jn. 18, 15-18 y 25-27). Estructuralmente los relatos son similares y concluyen con la amarga sentencia: "Antes de que cante el gallo, me negarás tres veces" (Mt. 26, 75). De esta forma, la voz del gallo contiene implícitamente la voz de Cristo y funciona como advertencia al apóstol, al tiempo que refuerza una frase que anteriormente los doce oyen en boca de Jesús, quien les reprocha cuando los encuentra dormidos: "¿Conque no habéis podido velar por una hora conmigo? Velad y orad, para que no caigáis en tentación. El espíritu está dispuesto, pero la carne es débil” (Mt. 26, 40-42. La cursiva es nuestra). La repetición del verbo velar, primero en infinitivo y luego en su forma imperativa, actúa como preludio al galicinio y de este modo, cuando el canto del gallo resuena en el silencio de las primeras horas del día, su voz se resemantiza: No solo es la advertencia de Cristo a Pedro sobre la negación, sino también el recuerdo de aquel sueño-tentación, que no les permitió permanecer vigilantes, tal y como la imagen del gallo lo sugiere.

\section{La generación del basilisco}

Isidoro de Sevilla incluye al basilisco dentro del capítulo de las serpientes; curiosamente, no lo coloca entre los monstruos ni portentos sino como una variedad de los ofidios.

Basilisco es nombre griego; en latín se interpreta régulo, porque es la reina de las serpientes, de tal manera que todas le huyen, porque las mata con su aliento y al hombre con su vista; más aun, ningún ave que vuele en su presencia pasa ilesa, sino que, aunque esté muy lejos, cae muerta y es devorada por él.

Sin embargo, le vence la comadreja, que los hombres lanzan a las cavernas en las que se esconde el basilisco. Cuando éste la ve huye y es perseguido hasta que es muerto por ella. Nada dejó el Padre de todas las cosas sin remedio. Su tamaño es de medio pie y tiene líneas formadas por puntos blancos.

Los régulos, como los escorpiones, andan por lugares áridos, pero cuando llegan a 
las aguas se hacen acuáticos.

Sibilus es el mismo basilisco, y se le da este nombre porque con su silbido mata antes que muerda (ISIDORO DE SEVILLA, Etimologías, XII, iv: 297). basilisco en diversos autores hasta la cristalización en la Vulgata, lo que da cuenta de una aceptación y difusión del mito y la tradición en el medioevo europeo. En la versión de Jerónimo, aparece el término basiliscus para traducir la voz hebrea serpethen ('serpiente venenosa', 'cobra').

Siglos más tarde la versión bíblica castellana de Casiodoro de Reina (1569), revisada a comienzos del siglo XVII por Cipriano de Valera, generalizaría el uso de basilisco en los lugares en lo que la Vulgata había empleado régulo. [...]. La revisada versión bíblica moderna conocida como Biblia de Jerusalén sustituyó cuidadosamente el basilisco por la víbora o la sierpe venenosa, aunque quizás por falta de referentes contextualmente creíbles prefirió respetar, en cambio, menciones no menos fantásticas [que aludían a los dragones terrestres y voladores] (Moure, 1999: 194).

Sobre los huevos, Isidoro afirma en el capítulo dedicado a las aves que "Algunos huevos se conciben sin concurso masculino; pero no pueden producir nunca pollos más que los concebidos con el macho y penetrados del humor seminal. Tanta es la fuerza de los huevos, que la madera rociada con huevo no arde, ni aun siquiera las vestiduras en las mismas condiciones. Mezclado con cal pega los fragmentos de vidrio" (ISIDORO DE SEVILLA, Etimologías, XII, vii: 315). Ciertamente, según Isidoro, los huevos poseen cualidades extraordinarias que podrían llegar a alterar las propiedades regulares de los elementos; el ejemplo lo da el mismo autor cuando sostiene que el fuego ya no podrá arder sobre la madera si esta hubiera sido previamente rociada con el contenido de estos huevos. El fuego no quema y el vidrio quebrado puede volver a unirse. Entonces, es posible que el huevo presente propiedades no relacionadas intrínsecamente con el principio vital sino con cierto pragmatismo: qué cosas se puede o no hacer con su contenido. Además, el contenido del huevo puede provocar un desorden del principio vital, vale decir, generar un ser vivo que quiebre las características naturales. Y si la nueva generación no se asemeja a la anterior, en un sentido aristotélico, estamos en el plano de lo monstruoso, encarnado por el basilisco (ARISTÓTELES, Historia de los animales, 585b, 586a). Por otra parte, cabe destacar una dualidad entre el huevo bendito, que representa la resurrección $-\mathrm{y}$ es, por tanto, imagen isomorfa del nacimiento y de la vida $-\mathrm{y}$ el huevo de los reptiles, considerado como huevo maldito, ligado al imaginario de los malos espíritus, los íncubos y súcubos (CHARBONNEAU-LASSAY, 1997: II, 676-677).

21 La visión planteada por Isidoro se irá reformulando a lo largo de la Edad Media y el Renacimiento, para decantar en la representación más frecuente del basilisco, un híbrido compuesto por la unidad gallo-serpiente: "cabeza y ocho patas de gallo, cola de serpiente trífida en la punta, y en la cabeza una corona y ojos centelleantes. Esta vinculación genésica con el gallo fijó su impronta en la etimología popular denunciada por la forma basilicoc (y su variante invertida caqbasile) del francés antiguo, la que a su vez explica la voz basilicok empleada en [...] inglés" (MOURE, 1999: 195). En la hibridación 
del basilisco queda implícita la oposición entre el gallo y la serpiente, es decir, entre Cristo y el demonio. Si el gallo es una imagen crística y su voz, la llamada de Cristo; la serpiente encarna la figura demoníaca. Cuando ambos animales se reúnen bajo el principio de hibridación monstruosa propio del basilisco, este puede leerse como la imagen del Anticristo por excelencia. Así lo pone de manifiesto el profeta Isaías cuando dice: "De la raza de la serpiente nacerá el basilisco,/parirá al dragón volante" (Is. 16, 29).

El mito de nacimiento del basilisco apunta a la gestación por parte de un gallo viejo, que pone un huevo por sí mismo o como resultado de la copulación con otro gallo. En la mayoría de los casos, dicho huevo descansa sobre el estiércol y es incubado por un sapo, una víbora o un búho. Vicente de Beauvais sostiene que "algunos autores pretenden que ese huevo no tiene cáscara, sino una especie de piel tan dura que los más violentos esfuerzos no pueden desgarrarla" (Vicente de Beauvais, apud CHARBONNEAU-LASSAY, 1997: II, 643). Analicemos las circunstancias que ponen en evidencia el carácter monstruoso del basilisco, a partir de su génesis. En primer lugar, hay que observar la ausencia de la gallina, es decir, tenemos un principio masculino representado por el gallo, que actúa individualmente o junto a otro masculino; esto es exactamente lo contrario de lo que afirmaba Isidoro, para quien ciertos huevos - aquellos que no contienen el germen de un polluelo- pueden ser concebidos "sin concurso masculino". En segundo lugar, la incubación se realiza sobre el estiércol, es decir, sobre la materia orgánica en descomposición que remite a lo escatológico. En tercer lugar, es importante llamar la atención sobre los animales que incuban el huevo: el sapo, la víbora y el búho, asociados con el bestiario demoníaco. A propósito de la versión que se refiere al sapo como agente incubador del huevo, escribe Pierre de Beauvais:

Cuando el gallo ha cumplido siete años, le nace un huevo en el vientre. Y cuando siente este huevo, permanece maravillado de sí mismo, y siente la mayor angustia que pueda sufrir un animal. Entonces, busca discretamente un lugar cálido, en un estercolero o en un establo, y araña con las patas hasta que excava un agujero en el que poner su huevo. Y cuando el huevo tenga su nido preparado, el gallo correrá allí más de diez veces diarias, pensando constantemente en desembarazarse de él. Y el sapo es de tal índole que percibe por su olfato el veneno que lleva el gallo en el vientre; inmediatamente se pone al acecho, de forma que no pueda el gallo ir al foso, sin que el sapo lo vea. Y en cuanto el gallo se aparta del lugar en el que debe poner el huevo, allá está inmediatamente el sapo, por ver si el huevo está puesto. Pues el sapo es de tal índole, que toma el huevo y lo incuba, si puede acercarse a él de alguna manera. Y cuando lo ha incubado tanto, que ha llegado el tiempo de la eclosión, resulta un animal que tiene cabeza, cuello y pecho como los del gallo; y desde el pecho hacia abajo, es como una serpiente. Y en cuanto puede valerse [por sí mismo] este animal, busca un lugar oculto en una vieja grieta, o en una cisterna abandonada; y allí permanece, para que nadie pueda verle. Pero es de tal naturaleza, que si el hombre puede verle antes de que él vea al hombre, muere; y si él ve al hombre antes, es el hombre quien morirá. Pues el animal es de tal naturaleza, que arroja su veneno por los ojos; y tiene la mirada tan venenosa, que mata a las aves que vuelan por encima de él, si puede mirarlas entre los ojos. [...]. Y no puede pasar por un lugar, sin que éste pierda su virtud; pues jamás volverá a producir, ni hierba ni otra cosa alguna. Y si toca un árbol, éste pierde su virtud, y jamás dará fruto; ha de perecer y secarse. [...]. Quien desee matar a este animal, deberá tener un claro recipiente de cristal o de vidrio, a través del cual pueda ver a la bestia. Pues al tener el hombre la cabeza tras el vidrio o el cristal, el basilisco no puede distinguirlo, y su mirada es detenida por el cristal o el vidrio; cuando el basilisco arroja su veneno por los ojos, es de tal naturaleza que, si choca contra 
algún objeto, rebota hacia atrás contra él, y ha de morir (PB: Cahier II, 213-215, apud

MALAXECHEVERRÍA, 1986: 159-160). procura deshacerse de él lo antes posible, mientras que el sapo "percibe por su olfato el veneno que lleva el gallo en el vientre" y acecha el huevo hasta incubarlo él mismo, contribuyendo a la generación teratológica. Esto pone de relevancia, una vez más, la oposición benévola/malévola entre el gallo y el basilisco respectivamente. Asimismo, el pasaje citado hace hincapié en la pestilencia propia del basilisco, que corrompe todo paisaje, fruto, hierba o animal que se halle a su alcance, como así también en la propagación del veneno a partir de los ojos. Sobre este último punto volveremos con más detenimiento en el próximo parágrafo, en relación al Palmerín de Olivia. Finalmente, si bien Isidoro y otros comentaristas habían indicado que la comadreja resultaba mortal para el basilisco ${ }^{4}$, también debe tenerse en cuenta que este sucumbe al canto del gallo, por esta razón era frecuente que los viajeros que temieran encontrar basiliscos en su camino se acompañaran de un gallináceo crestado macho, así como también de un espejo, arma más que efectiva, dado que neutralizaba el poder de la mirada, volviéndola en contra del propio monstruo. Sin duda, un eco del mito de Perseo y Medusa.

La moralización cristiana sobre el basilisco aparece en diversos pasajes. Uno de ellos pone el acento en la diferencia entre el aspecto exterior e interior, cuando afirma: "No obstante, es un bello animal, de hermoso color manchado de blanco. Pero otro tanto sucede con muchas cosas que son atractivas, pero malas" (PB: Cahier II, 213-215, apud MALAXECHEVERRÍA, 1986: 160). La cita tematiza la belleza engañadora, cuestión que aparece ligada al ámbito demoníaco en numerosos tipos discursivos, donde a menudo son las mujeres quienes actúan como instrumento del demonio y conducen al hombre a la tentación. En el mismo bestiario de Beauvais, se explica el símbolo demoníaco del monstruo:

Este animal representa al diablo, al mismo Satanás que se escondió en el paraíso, que engañó a Eva y a Adán; así comieron del fruto prohibido. Por eso fueron expulsados del paraíso, y cuando murieron, fueron a caer a la cisterna del infierno. Así fueron envenenados, ellos y todos los descendientes de Adán durante cuatro mil años, que murieron todos y cayeron a la cisterna, con el basilisco, es decir, el infierno, con el demonio. El hijo de un rey se dolió de que este animal fuera tan venenoso, y que matase a todo el mundo; y que nadie pudiese matar o contemplar a la bestia. Entonces, entró el hijo del rey a un recipiente mucho más transparente que el vidrio o el cristal; entended que el Hijo de Dios entró en el cuerpo bendito de Nuestra Señora, la Virgen más clara y limpia, María su madre. Entonces, el basilisco arrojó por los ojos su veneno, al contemplar el recipiente en el que se encontraba el hijo del rey; y el veneno chocó contra el recipiente, sin poder hacer daño a nadie, salvo a la bestia. Entonces, rebotó el veneno sobre el animal, y éste permaneció languideciente hasta que el hijo del rey se encontró fuera del recipiente en el que se hallaba; entended que Nuestro Señor Jesucristo estuvo en el vientre de su madre, por lo que el Enemigo languidecía hasta que fue clavado en la cruz, donde murió. Y cuando Dios fue llevado a Su sepulcro, y resucitó al tercer día, el hijo del rey, Jesucristo, entró en la cisterna vieja, y sacó de ella a todos sus amigos, a los que el basilisco había atraído y matado con su veneno, desde que Adán cayera dentro; y condujo a la claridad y a la alegría a todos a los que se llevó consigo. Entended que Dios arrebató a sus amigos del infierno, merced a la muerte que quizo sufrir por Su pueblo (PB: Cahier II, 213-215, apud MALAXECHEVERRíA, 1986: 160-161. La cursiva es nuestra).

El verbo representar implica la analogía propia de los bestiarios (A es a B, como C es a D) y la triple repetición del imperativo entended es seguida de la explicación cristiana de 
cada uno de los pasajes. En la misma línea moralizante, el Bestiaire d'amour rimé afirma que "existe una mala gente/llena de mala visión;/[...]/esta gentuza de mal origen/por su mirada traidora y repugnante/tal gente parece el basilisco" (B. d'amour rimé, vv. 3212-3234, apud MALAXECHEVERRÍA, 1986: 160-161).

\section{El basilisco palmeriniano: mito y reconstrucción caballeresca}

El Palmerín de Olivia (Salamanca, Juan de Porras, 1511), publicado tres años después que el Amadís, es el primero de los libros que componen el ciclo español palmeriniano, seguido del Primaleón (1512) y el Platir (1513)5. Tal como corresponde a la figura heroica, el protagonista intentará imponer el orden sobre el desorden, representado, entre otros personajes, por el monstruo. En el caso de los libros de caballerías, el arquetipo heroico se identifica con el guerrero cristiano, quien debe vencer una serie de obstáculos para transformar el $\operatorname{caos}^{6}$ en cosmos, siguiendo los principios del cristianismo. Partiendo de esta premisa, Aquilino Suárez Pallasá sostiene que

el modelo supremo de toda caballería es el propio Dios, puesto que, impulsado por amor infinito al mundo y al hombre, por la encarnación del Verbo en Jesucristo, verdadero Dios y verdadero hombre, cumplió el itinerario infinito que separa el Cielo de la Tierra, la Eternidad del Tiempo, la Divinidad de la Humanidad, deviniendo Héroe entre nosotros para superar la máxima Aventura. [...] Este es el modelo de todos los modelos (sUÁrezZ PALLASÁ, 2006: 3-6).

Así como Dios dotó de forma un universo informe, el caballero debe hacerlo con el mundo que encuentra a su paso. Hacer justicia con los débiles, combatir con los caballeros felones, recuperar territorios usurpados por tiranos, dominar a los seres monstruosos, entre otros desafíos, forman parte de la transformación del caos en cosmos porque, en última instancia, el caballero realiza la repetición del acto primordial de la Creación, a través de la re-creación del orden cósmico en un plano mítico (ELIADE, 2006; CAMPBELL, 1998). En la misma línea, Javier Roberto González afirma que todo caballero andante "impone un orden [...] sobre un mundo que se presenta en principio como caótico, anómico, regido por la mala costumbre o la monstruosidad; pero el ordenamiento del caos implica asimismo una conversión interna, un mejoramiento propio del caballero, que al ordenar se ordena, se eleva, se redime" (GONZÁLEZ, 2006: 120-121). En consecuencia, todo héroe se define como un "hacedor de orden" y a esto se reduce el sentido primordial de la batalla arquetípica que se libra con el monstruo: imponer la forma a la materia, la voluntad racional sobre la esfera irracional-salvaje.

El Palmerín de Olivia muestra una amplia teratología, como puede verse a través de las figuras antagónicas de la sierpe/dragón ${ }^{7}$, el sagitario o centauro ${ }^{8}$ (PO, cxiii), el basilisco ${ }^{9}$ (PO, cxxix), los gigantes ${ }^{10}$ (PO, xxiii, xxiv, xxv, lvi, lvii) y los enanos ${ }^{11}$ (PO, xix, xxii, xxxi, xxxii, xxxiii, lxv, lxvi); y dos animales monstruosos -en el sentido del prodigiorepresentados por los leones reverentes ${ }^{12}(\mathrm{PO}, \mathrm{lxxix})$ y el ave profética ${ }^{13}(\mathrm{PO}, \mathrm{cxxv}$, cxxxiii). Todos ellos responden al imaginario de los monstruos tradicionales, algunos están asociados con las razas monstruosas pero ninguno constituye una novedad per se, del mismo modo que los animales palmerinianos siguen las cualidades de los bestiarios y las historias naturales pero no se detienen en una descripción exhaustiva. En suma, la aparición del monstruo en el Palmerín es siempre negativa, atendiendo a las normas del 
género, que presenta al ser teratológico como una de las fuerzas antagonistas que el héroe debe derrotar cuerpo a cuerpo para restaurar el orden cósmico. Tal como sostiene Marín Pina:

Reales o imaginarios, encantados o desencantados, los componentes de este bestiario palmeriniano son variantes de un tipo caballeresco perfectamente fijado por el género y erigido como una temida fuerza antagónica del héroe. Su figura, desemejada con los pinceles de la descriptio, se convierte en un agresor potencial del orden social, vencido únicamente por el héroe en un combate singular (MARín PINA, s/d: 205-206).

A diferencia de otras fuentes donde la existencia de lo monstruoso se vincula con la diversidad del mundo creado y no siempre representa una amenaza, en los libros de caballerías el monstruo encarna el mal y su fealdad exterior traduce su fealdad interior o moral, siguiendo la identificación tradicional horridum-malum, propia de la estética medieval. Así, "la descripción física (descriptio superficialis) y la espiritual (descriptio intrinseca) no es necesaria para la incorporación de personajes al texto, ya que basta [...] con la alusión a su condición (gigante, enano, monstruo) para su inserción" (MARín PINA, $\mathrm{s} / \mathrm{d}$ : 428) en el relato. Por eso, existen dos alternativas frente al ser teratológico en los relatos caballerescos: o se elimina o se convierte. Esto último ocurre cuando el sujeto monstruoso se hace cristiano y, por ende, se vuelve aliado del héroe. $\mathrm{O}$ cuando los animales que integran la zoología monstruosa se domestican, es decir, pasan de una condición de salvajismo a una de mansedumbre, a través de la acción heroica y/o del reconocimiento de la valía del héroe.

En el Capítulo CXXIX, Palmerín decide ir en busca del mago Muça Belín, a fin de encontrar una solución para la salud de la Infanta Zerfira. Marchan a través del "señorío del Soldán de Persia" y en el camino sortean muchas pruebas, que el narrador resume en los éxitos del héroe: "e en otros lugares se vieron en grandes peligros con cavalleros e con otras gentes, mas de todo esto los libró Dios e el grande esfuerzo de Palmerín" (PO, CXXIX: 282). Con esto que se repite el esquema de Dios como agente salvífico y dador de la victoria al caballero, pues si el buen caballero cuenta con el sustento del Dios cristiano la aventura llegará siempre a buen puerto. Una prueba más de ello será el enfrentamiento con el basilisco, que tiene lugar en el mundo oriental, donde transcurre gran parte de la obra.

E avínoles que entraron un día por una grande montaña que avía bien dos jornadas en ella e esto les causó errar el camino como no sabían la tierra e tomóles la noche en lo más espesso de la montaña, e como yva tanta compaña no temían cosa alguna e fallaron un lugar muy bueno e allí armaron las tiendas para la Ynfanta e fezieron grandes lumbres para fazer de cenar. E desque todos uvieron cenado, la Ynfanta se echó a dormir e ansí todos los otros, salvo dos hombres que mandaron velar porque estavan en aquel lugar; mas ellos como venían cansados dormiéronse ansimismo. Palmerín en todo aquel camino quando dormía en el campo nunca se desarmava e ansí armado se echó en su tienda e, como su coraçón era tan cuytado con desseos de su señora e por la ventura que le avían acaecido no siendo cierto de tornar a cobrar a sus amigos, todas las más de las noches pensava en su fazienda gran pieça; e ansí aquélla.

E estando ansí vido venir por la montaña tan gran claridad como si fuera de una hacha encendida. Él se maravilló e levantóse muy apriessa e enlanzó su yelmo e tomó su espada e salió fuera de la tienda e vido una cosa muy desmejada que parescía en la fechura cabrón, mas era tan maño como un cavallo e traýa en la fruente dos cuernos muy agudos e derechos y en medio d'ellos traýa una piedra de que salía aquella claridad a manera de olicornio, mas no lo era; e llámase aquel mostruo en aquella tierra basilisco, e era tan bravo e esquivo que más no lo podía 
ser: tenía los dientes e uñas muy agudas, e ansí como llegó a la compaña de la Ynfanta tomó un hombre entre sus uñas e fízolo pedazos muy presto. Palmerín que lo vido fue muy espantado e dixo:

-¡Ay Santa María, valedme, no consintáys qu'este diablo nos pueda empeçer mal! (PO, CXXIX: 285-283).

31 La montaña donde ingresan se percibe fácilmente, para el lector de caballerías, como uno de los espacios propios del monstruo. Tal como explican Simone Guidi y Antonio Lucci:

il mostro -è cosa nota - vive in luoghi inesplorati; luoghi geografici, dei quali é il custode, il sovrano, l'usurpatore o il semplice inquilino, e luoghi interiori, in cui abita e tesse nascostamente la sua tela, attore dell'inumano, specchio deformante e difformante dell'io, parola non detta, immagine aberrata. Spazi umani -anzi, spazi peculiarmente umani- giacché l'ospite e il destinatario ultimo del monstruoso è l'uomo stesso, como mostra e racconta gran parte della teratología e della sua storia (GUIDI y LUCCI, 2012: 5-6).

Del mismo modo, en el plano simbólico, la noche es el tiempo propicio para la llegada del mal, amén de las reflexiones personales y los encuentros amorosos, que en este caso no se producen. El basilisco se presenta cuando todos se han quedado dormidos, incluso los caballeros que tenían la obligación de velar por el resto de la compañía. La acción de 'velar' introducida por el narrador no es casual sino que responde a un imaginario simbólico, acorde con el resto del episodio. Su aparición funciona como un nexo contrapuntístico que se liga al episodio bíblico de la oración en el huerto de Getsemaní, cuando Cristo y sus discípulos están orando pero ellos se quedan dormidos. La entrada del basilisco, por lo tanto, sintetiza el imaginario evangélico que, sin duda, refuerza la lectura del monstruo como símbolo del mal. Palmerín, como buen cristiano, no duerme sino que se recuesta armado, listo para el combate en todo momento.

La llegada del basilisco se percibe primero como la visión de una gran claridad, "como si fuera una hacha encendida", que proviene de la piedra que lleva entre los cuernos. La hibridez de la que da cuenta el relato no responde a la clásica unión entre gallo y serpiente, sino que se menciona la confusión inicial entre el "cabrón", el "cavallo" y el "olicornio", y solo después se advierte que se trata de un basilisco. Cabe hacer hincapié en la presencia de los "dos cuernos muy agudos e derechos" con que se caracteriza al monstruo. El cuerno frontal en los animales ha sido visto como un símbolo de fuerza, poder, mando y dominio. Mientras que el cuerno único es isomorfo de la cabeza y la frente erguidas, la cola de los animales y el pene en erección, ya que "en la anatomía animal es el cuerno, imputrescible y cuya forma oblonga es directamente sugestiva, lo que va a simbolizar admirablemente la potencia viril, tanto más cuanto que son los animales machos los que llevan los cuernos" (DURAND, 2004: 147); los dos cuernos simbolizan para el cristianismo los principios del Bien y del Mal, así como los personajes cornudos encarnan con frecuencia los vicios y pecados capitales. Por lo tanto, los dos cuernos del basilisco palmeriniano pueden leerse como un refuerzo de la bipolaridad Cristo/Anticristo. Ahora bien, ¿por qué la posible confusión con el unicornio que nos advierte el narrador? Ante todo, el unicornio medieval se asocia con un doble imaginario ligado tanto a "la salvaguardia de la virginidad (el cuerno único levantado hacia el cielo)" como a la "fecundidad (sentido fálico del cuerno)" (chevalier, 1986: 1037-1039). Por eso se lo considera una imagen propicia para representar la encarnación del Hijo de Dios, es decir, una fecundidad que no corrompe la virginidad. Por otro lado, tanto el basilisco como el unicornio son extremadamente difíciles de atrapar; mientras que el primero solo puede capturarse con ayuda de un espejo que 
hace de escudo y proyecta el envenenamiento o la mirada letal sobre el propio monstruo, el segundo necesita la presencia de una doncella que logre adormecerlo con el perfume que emana de la leche virginal. Como consecuencia, la distinción del narrador entre el unicornio y el basilisco viene a reforzar la dicotomía Cristo/ Anticristo, virginidad/sexualidad, espíritu/carne. Finalmente, cabe añadir el vínculo simbólico del cuerno con la corona, alineados en una estructura de poder. Así lo explica René Guénon, quien afirma que la raíz KRN- está presente en la base de los nombres cuerno y corona, lo mismo que ambos términos se hallan muy próximos en el latín (cornu y corona, respectivamente). Precisamente, entre los rasgos del basilisco tradicional decíamos que figura como el rey de las serpientes y es, por tanto, coronado. Explica Guénon:

Es demasiado evidente que la corona es la insignia de poder y la señal de una jerarquía elevada para que resulte necesario insistir en ello; y encontramos una primera relación con los cuernos en el hecho de que éstos también están situados en la cabeza, lo cual da bien la idea de una "sumidad". Empero, hay algo más: la corona era primitivamente un aro ornado de puntas en forma de rayos; y los cuernos, análogamente, se consideran como figuración de los rayos luminosos, lo que nos reconduce a algunas de las exposiciones que hemos hecho acerca de las armas simbólicas. Está claro, por lo demás, que los cuernos pueden asimilarse a las armas, incluso en el sentido más literal, y también así ha podido vincularse una idea de fuerza o potencia (GUÉNON, 1969: 168).

Por su parte, Jung encuentra en los cuernos tanto un principio activo y masculino -por la penetración-, como un principio pasivo y femenino - por su sentido de receptáculo -; como resultado de la unidad de ambos principios, el hombre lograría llegar a la etapa de madurez, de equilibrio, de armonía interior (CHEVALIER, 1986: 390). Siguiendo esta lectura, creemos que el hecho de reunir ambos principios sexuales podría conducirnos a una segunda imagen del cuerno: el poder andrógino ${ }^{14}$, identificado con la serpiente uróboros.

Otro elemento simbólico que se destaca en la descripción del monstruo es la piedra brillante que el basilisco lleva entre los cuernos. Culminada la batalla con el basilisco, la Infanta Zerfira le pide a Palmerín que extraiga la "piedra muy preciosa de que salía aquella lumbre [...] porque era de gran virtud, que resteñava la sangre de las llagas e dava fuerça al corazón" (PO, CXXIX: 283). Este hecho responde al tópico del monstruo como guardián de tesoros, es decir, el ser teratológico que guarda celosamente la entrada a un espacio que alberga un objeto precioso o, como en este caso, el propio monstruo tiene en su morfología un elemento mágico que actúa como remedio. Por su parte, Jean Chevalier hace referencia a "la piedra caída de la frente de Lucifer, en la cual, según Wolfram de Eschenbach, fue tallado el grial" (CHEVALIER, 1986: 828), cuestión que pone el acento en la demonización del basilisco palmeriniano, vinculándolo directamente con el demonio. Asimismo, las tradiciones orientales distinguen entre: a) el ojo físico, b) el ojo frontal, también llamado el tercer ojo de Shiva y c) el ojo del corazón. Creemos que la piedra del basilisco puede leerse como un isomorfo del segundo por dos razones. Primero, la esencia del tercer ojo se corresponde con el fuego $\mathrm{y}$, por tanto, su mirada reduce todo a cenizas, precisamente una de las características del basilisco, capaz de matar con la mirada. Segundo, la existencia de un solo ojo indica una condición infrahumana propia de los monstruos, que connota un sentido de vigilancia constante hacia el exterior, por lo que podríamos nuevamente leer este isomorfismo piedra/ojo del basilisco como contrapartida de la imagen originaria del gallo, en tanto vigilante diurno. 
Según hemos venido analizando, la imagen del basilisco palmeriniano no se ajusta por completo a la que nos ofrecen los bestiarios. Acaso por esa razón el basilisco es el monstruo sobre el que se ofrece la mayor descriptio de toda la obra, porque si bien no es un "monstruo nuevo" los elementos que retiene del basilisco tradicional son escasos. Sin embargo, precisamente los rasgos que se conservan son aquellos de carácter esencial. La serpiente no aparece descripta de modo directo pero se pone de manifiesto en la batalla cuando Trineo -que conserva todavía la apariencia de un can, por efecto de una metamorfosis mágica- "fuele ayudar e travóle la cola e teníalo tan fuerte qu'el basilisco no se podía menear como quería" (PO, CXXIX: 283). La sinécdoque cola pone de relieve un rasgo serpentino definitorio, por lo que se deja entrever la imagen de uno de los animales que componen el basilisco arquetípico. Las otras características que se conservan son la piedra de virtudes mágicas, ubicada en la frente del monstruo, y las uñas filosas. En cambio, los cuernos constituyen un elemento novedoso para el basilisco, que refuerza su interpretación como Anticristo. El tópico de la muerte a la distancia, que se logra a partir de la mirada y del aliento, no parece tener importancia para el autor del Palmerín. Podríamos arriesgar nuestra interpretación a propósito de esos vacíos textuales. Creemos que, en realidad, lejos de estar completamente ausentes, ambos se presentan resemantizados en otros símbolos. En lo que concierne a la mirada, lo que ocurre es una transformación del polo negativo en positivo, un desplazamiento desde la mirada mortífera hacia la piedra mágica, que contiene virtudes curativas ("resteñava la sangre de las llagas") y espirituales ("dava fuerça al corazón"), teniendo en cuenta su isomorfismo con el ojo, de acuerdo con lo que ya hemos demostrado; asimismo, un eco de las piedras de los gallos con propiedades sobrenaturales, tal como figuran en los bestiarios y las historias naturales. Por otra parte, el aliento pestífero del monstruo, capaz de anular la regeneración de los elementos de la naturaleza corromper la pureza de las aguas, impedir la fructificación de los árboles, hacer caer las aves volanderas, como así también los animales y los hombres que, al respirar el hálito emanado por el basilisco, mueren instantáneamente- no aparece de forma explícita como arma en la batalla que libra con los caballeros. No obstante, el texto refiere, con posterioridad a la muerte del monstruo, el "fedor" que emana de su cuerpo sin vida, razón por la que toda la compañía se ve obligada a irse de allí, ya que "no podían comportar el fedor del basilisco" (PO, CXXIX: 283). El aliento fétido del monstruo cobra mayor importancia una vez muerto, pero el narrador no lo presenta como arma de defensa durante el combate porque en ese punto lo relevante es el par de cuernos.

Dichos cambios no constituyen un problema mayúsculo para decodificar al basilisco palmeriniano, en orden a la representación tradicional que los bestiarios han hecho de este monstruo. Por el contrario, pueden explicarse a través de la transformación de los relatos, que Vladimir Propp analiza en los cuentos maravillosos. El vínculo entre estos y los libros de caballerías, al igual que su conexión con el relato mítico, ya ha sido suficientemente probado; de modo que esta explicación no puede considerarse como ajena al Palmerín de Olivia en general y al episodio del basilisco palmeriniano, en particular. Siguiendo esta premisa, creemos que es posible afirmar que las modificaciones que hemos venido analizando hasta aquí se ajustan a la transformación del relato por reducción. Esto significa que, pese a la ausencia de algunos elementos del basilisco tradicional, existe una "reducción que representa una forma fundamental incompleta" (PROPP, 2001: 204). Y las formas fundamentales existen. Existe la cola serpentina, existe el ojo único que reduce todo a cenizas y su isomorfismo con la piedra mágica, existe el olor mortífero, existen las uñas desgarradoras, existe su aparición 
nocturna que funge como antítesis del gallo diurno. Todos estos elementos, que hemos ido analizado detenidamente a lo largo de estas páginas, nos hacen pensar que, pese a las diferencias o a su aparente incompletud respecto del monstruo tradicional, el basilisco del relato palmeriniano persiste en su forma fundamental.

\section{Conclusiones}

La aparición del Fisiólogo, entre los siglos II y V en Alejandría, fija el modelo de bestiario medieval, que se irá engrosando en los siglos posteriores -incluso transformandopero mantendrá la esencia de enciclopedia animalística y monstruosa, cuyas interpretaciones siguen una visión de la moral cristiana. De este modo, los animales y los monstruos asumen características benéficas o maléficas, virtudes o vicios, en función de sus rasgos físicos, sus hábitos biológicos, su alimentación, etc.; que los colocan a la par de los hombres, reflejan sus conductas y sirven de espejo para la moralización propuesta. La autoridad inicial del Fisiólogo -el exégeta de la naturalezase complementa con las Sagradas Escrituras y así, cada animal/monstruo es interpretado para aleccionar a los hombres y simplificar las grandes cuestiones teológicas.

La influencia de esta obra fue tal que el uso simbólico zoomórfico y teratológico supo extenderse a diversos tipos discursivos, entre los que se hallan los libros de caballerías. A lo largo de estas páginas, hemos estudiado la imagen del basilisco a la luz de los bestiarios e historias naturales, a fin de arribar a la aparición que hace este tipo monstruoso en el Palmerín de Olivia, un libro de caballerías castellano sumamente influyente para la tradición de la caballería literaria. Aunque el basilisco es un monstruo híbrido de gallo y serpiente, es lícito seguir la premisa de Zucker cuando afirma que los animales (en nuestro caso, el monstruo híbrido, resultado de la combinación de dos animales) deben ser estudiados no solo en su contexto sino en situación, es decir, a partir de las acciones que realizan en el relato. El monstruo en cuestión, que se presenta como antagonista del héroe, introduce ciertas variantes sobre la imagen arquetípica del basilisco de los bestiarios. Al comienzo de la aventura caballeresca, la sierpe da ocasión para el combate iniciático del héroe; luego, el sagitario constituye el enfrentamiento consigo mismo; ahora, en este punto del relato -cuando Palmerín se halla en una nueva búsqueda- el basilisco encarna un tríptico simbólico. En primer lugar, es el Anticristo que vence el caballero cristiano para instrumentalizar la victoria divina; en segundo lugar, es el poder real sobre el que el héroe gana la confianza y va construyendo su propio nombre, que al final del camino lo consagrará como parte de la realeza cuando sea nombrado nuevo Emperador; finalmente, es otra cara del enfrentamiento consigo mismo. Consideramos que las modificaciones del basilisco palmeriniano pueden explicarse a la luz de las transformaciones de los relatos tradicionales, específicamente, consideramos la transformación por reducción, es decir, aquella donde se mantiene la forma fundamental incompleta. Si el sagitario implica para Palmerín la dominación del sí mismo, de su parte más animal, de la libido desenfrenada; el basilisco es la capacidad de mirarse a sí mismo, a fin de lograr la superación de los fantasmas interiores, acaso reflejados en el ojo de Shiva, que ha tornado la mirada fulminante de carácter demoníaco en la piedra mágica que salvará a Zerfira. 


\section{BIBLIOGRAFÍA}

\section{Fuentes}

Aristóteles, Historia de los animales, José Vara Donado (ed.), Madrid, Akal, 1990.

Bestiario medieval, Ignacio Malaxecheverría (ed.), Madrid, Siruela, 1986.

Covarrubias, Sebastián de, Tesoro de la lengua castellana o española, Ignacio Arellano y Rafael Zafra (eds.), Madrid, Iberoamericana 2006.

El Fisiólogo. Bestiario Medieval, Marino Ayera Redín y Nilda Guglielmi (tr.), Nilda Guglielmi (ed.), Buenos Aires, Eudeba, 1971.

Isidoro de Sevilla, Etimologías, Luis Cortés y Góngora, y Santiago Montero Díaz (eds.), Madrid, BAC, 1951.

Palmerín de Olivia, Ma. Carmen Marín Pina, Giuseppe di Stefano, Daniela Pierucci (eds.), Alcalá de Henares, Centro de Estudios Cervantinos, 2004.

Plinio, Historia natural, Jerónimo de la Huerta (ed.), Madrid, Luis Sánchez Impresor, 1624 (facsímil).

\section{Estudios críticos}

Caro Baroja, Julio, Las brujas y su mundo, Madrid, Alianza, 1993.

Charbonneau-Lassay, L., El bestiario de Cristo. El simbolismo animal en la Antigüedad y en la Edad Media, Barcelona, Sophia Perennis, vol. I y II, 1997.

Chevalier, Jean y Gheerbrant, Alain, Diccionario de los símbolos. Barcelona, Herder, 1986.

Cirlot, Victoria, "La estética de lo monstruoso en la Edad Media", Revista de Literatura Medieval, 2, 1990, 175-182.

Durand, Gilbert, Las estructuras antropológicas del imaginario: introducción a la arquetipología general, México, Fondo de Cultura Económica, 2004.

Eliade, Mircea, El mito del eterno retorno. Arquetipos y repetición, Buenos Aires, Emecé, 2006.

García Arranz, José Julio, "El Physiologus como fuente gráfico-textual de la emblemática animalística de la Edad Media", Janus, 3, 2014, 73-114.

Glockner, Julio, “Viejos y nuevos monstruos”, Elementos, Ciencia y Cultura, 22, vol. 3, 1994, 35-42.

González, Javier Roberto, "Pertinencia formal y funcional de la aventura maravillosa en los libros de caballerías: Cirongilio de Tracia, Primaleón, Las sergas de Esplandián", en Nuevos estudios sobre literatura caballeresca. Barcelona-Kassel, Reichenberger, 2006, pp. 111-164.

Guénon, René, Símbolos fundamentales de la ciencia sagrada, Buenos Aires, Eudeba, 1969.

Guglielmi, Nilda (ed.), El Fisiólogo. Buenos Aires, Eudeba, 1971.

Guidi, Simone y Luci, Antonio (eds.), Spazi del mostruoso. Luoghi filosofici della mostruosità. IX, ii, 2012. 
Malaxecheverría, Ignacio (ed.), Bestiario medieval, Madrid, Siruela, 1986.

Marín Pina, María Carmen, Edición y estudio del ciclo español de los Palmerines, Tesis doctoral, Zaragoza, Universidad (microfichas), 1988.

Marín Pina, María Carmen, "Los monstruos híbridos en los libros de caballerías españoles”, en Actas do IV Congresso da Associação Hispánica de Literatura Medieval, (Lisboa, 1-5 Outubro 1991), Lisboa, Cosmos, 1993, pp. 27-33.

Morales Muñiz, María Dolores, "El simbolismo animal en la cultura medieval”, Espacio, tiempo y forma, Serie III, H. Medieval, 9, 1996, 229-255.

Orsanic, Lucía, La mujer-serpiente en los libros de caballerías castellanos. Forma y arquetipo de lo monstruoso femenino, Madrid, La Ergástula, 2014.

Propp, Vladimir, Morfología del cuento, Madrid, Akal, 2001.

Siebers, Tobin, El espejo de Medusa. México, Fondo de Cultura Económica, 1993.

Suárez Pallasá, Aquilino, "Fenomenología de la obra caballeresca y Amadís de Gaula", en Lilia E. Ferrario de Orduna et alii. Nuevos estudios sobre literatura caballeresca. Kassel-Barcelona, Reichenberger, 2006, pp. 1-10.

Zucker, Arnaud, "Morale du Physiologos : le symbolisme animal dans le christianisme ancien (IIeVe s.)", Rursus, 2, 2007, 1-25.

\section{NOTAS}

1. Hemos estudiado la imagen de la mujer-serpiente en los libros de caballerías castellanos como monstruo arquetípico femenino (ORSANIC, 2014).

2. Un trabajo ejemplar a propósito de los animales en su contexto es el de María Dolores-Carmen Morales Muñiz (1996: 229-255), quien en sus estudios sobre las culturas zoológicas en la España medieval, establece una comparación entre la cristiana, la musulmana y la judía.

3. "Con un hierro caliente les queman las anquillas o les queman los espolones, y luego los untan con barro, quedan sin ningún celo y engordan. Lo ordinario es sacarles los testículos, y si no se hace con destreza se mueren" (COVARRUBIAS, Tesoro de la lengua castellana o española: 575$)$.

4. "Es vencido por las comadrejas que colocan los hombres en los agujeros de la tierra donde se esconden. En cuanto ve una, escapa, pero ella le persigue y lo mata. En efecto, el Padre común no ha creado nada sin su remedio" (De Bestiis, 214, apud MALAXECHEVERRÍA, 1986: 159). La cita evidencia la moralización cristiana cuando alude a la Creación divina como una cuestión que no deja nada librado a su suerte.

5. Tradicionalmente, el ciclo ha sido ampliado con otros tres libros, a saber: Polindo, Palmerín de Inglaterra y Flortir, los cuales no forman parte del ciclo español para María Carmen Marín Pina (s/ d).

6. Para la relación del monstruo con el caos, cfr. CIRLOT, 1990: 175-182.

7. "E como el sol fue salido, la sierpe salió de la cueva; y estava un llano delante d'ella donde havía mucha yerva verde e muchos huesos ansí de hombres como de bestias que la sierpe havía despedazado he comido. [...]. La sierpe començó de comer la carne que allí tenía e después que se faltó echóse a la callentura del sol. [...] E salió de entre las matas con la maça en las manos e fue muy passo; e como se vido en el campo juntó muy presto con ella e diole tan fuerte golpe encima de la cabeça con la maça de fierro que la aturdió toda, e dio tan gran bramido como se sintió malherida que toda la montaña parescía que se hundía, e alçó las manos e tomó a Palmerín entre sus muy fuertes uñas e rompióle la loriga e físole muy grandes llagas. El se esforzó lo mejor que 
pudo e tornóle a dar otro golpe por cima de la cabeça, muy pesado, e aunque ella tenía el cuero muy duro fue tal el golpe que los sesos le fizo saltar" (PO, XVII: 41). En todos los casos, citamos según la edición crítica de Giuseppe di Stefano. [Palmerín de Olivia] El libro del famoso e muy esforçado cavallero Palmerín de Olivia [1511, 2004]. Introducción de Ma. Carmen Marín Pina; edición y apéndices de Giuseppe di Stefano; colaboración de Daniela Pierucci. Alcalá de Henares, Centro de Estudios Cervantinos.

8. "Otro día entraron en el torneo más de mill e quinientos cavalleros e todos eran tan buenos que viérades fazer maravillas e muchos yvan a tierra de los fuertes golpes que recibían. E andando el torneo muy mesclado sobrevino a él una fuerte ventura, que entró por una de las puertas un sagetario que era medio hombre e medio cavallo, e traýa las armas que le cobrían de un muy fuerte e duro cuerno e de aquello mismo era el escudo, e la espada suya, era muy buena e tajante e él era tal que sabía muy bien escremir con ella. E este sagetario era criado en la ysla de Eliquias e era señor de aquella ysla un cavallero, el más ardid e sobervio que avía en el mundo, e oyó dezir de aquellas fiestas que se fazían en Constantinopla e cómo su juntavan allí muchos buenos cavalleros. [...]. E como entraron en el cerco començaron ambos a dos a dar golpes por los cavalleros de la parte de Frisol e finieron tanto en poca de ora que más de ciento fueron a tierra. Fue el ruido tan grande e las bozes de los unos e de los otros qu'era maravilla. El Emperador fue muy mal espantado e todos los qu'estavan con él. Palmerín bien conosció, según la fuerça de aquellos dos, que avían de fazer gran daño e sin mucho detenerse en dezir nada fuesse apriessa al palacio e armóse de sus ricas armas e mandó que le ensillaran un cavallo muy bueno. [...] Aunque el sagetario vido todos los cavalleros fuera, por eso no dexaba de dar golpes a todos los que delante de sí fallava, que no sabía la condición del torneo e punavan d'echar aquéllos fuera porque quedassen vencedores. [...] Llegó Palmerín e entró en el torneo con grande ardimiento e púsose ante todos e sacó su espada e fue ferir al sagetario que con muy gran corazón lo esperó. E viérades entre ellos una esquiva batalla [...] Mas Palmerín, que de gran corazón e fuerça era, andava tan bravo e dava tales golpes al sagetario que no avía hombre que lo viesse que no se espantasse; mas sus armas eran tan fuertes que poco le empecía la buena espada de Palmerín, salvo que andava ya cansado. Palmerín gelo sentió en los golpes que no dava tan fuertes como quando començaron la batalla e puso las espuelas al cavallo muy rezio e juntó muy presto con el sagetario e con los pechos del cavallo lo embarazó de tal manera que dio con él en tierra e después passó dos vezes por encima d'él, de manera que lo dexó tan quebrantado que no se pudo levantar" (PO, CXIII: 245-246. El subrayado es nuestro).

9. Suprimimos aquí la cita porque es el monstruo que trataremos en detalle.

10. Es el único caso de la obra donde el monstruo aparece como un colectivo, pues se trata de una familia de gigantes. Ello supone, por un lado, un refuerzo del monstruo singular y, por otro lado, la posibilidad de presentar la monstruosidad femenina, a través del personaje de la giganta. Los motivos de venganza familiar harán que la aparición de este tipo de monstruo no se reduzca a un único encuentro sino que se prolongue a lo largo de una serie de capítulos. La descripción del gigante Murdaneo es bastante breve; se trata del hijo de Damarco, a quien Palmerín va a buscar: "E no tardó mucho que no vino el fijo del jayán, que era tan grande e tan feo que espantava a los que lo miravan" (PO, XXIIII: 57). Palmerín le da muerte y más adelante, se enfrenta con Damarco y su esposa, a la que el narrador presenta del siguiente modo: "Su muger, que esto vido, apeóse muy apriessa e tomó la lança de su marido a un escudero que la traýa e sin ningún pavor fue ferir a Palmerín con ella, e si él no gela cortara con la espada hubiéralo muerto con ella. La ja[ya]na como una leona raviosa se quería abraçar con él, mas a Palmerín fuele forçado matalla, aunque a él se le hizo vergüenza por ser muger, e dióle tal golpe por la cabeça que luego cayó muerta cabe su marido" (PO, XXV: 59). Finalmente, Palmerín enfrentará al gigante Franarque, el hermano de Damarco, que pretenderá llevar a cabo la venganza de sangre, a quien el héroe también vencerá (PO, LVII). 
11. En el Palmerín, hay dos enanos. Por un lado, está Urbanil, que desempeña el papel de escudero del héroe y es heredero del Ardián, el enano amadisiano, y por otro lado, hay un enano sin nombre propio. A ambos socorre el héroe pero solo con el primero estrecha lazos que hacen del enano un personaje permanente a lo largo de la obra, codo a codo con Palmerín, pero ninguno de los dos enanos da lugar a la descripción morfológica. En paralelo con los gigantes, ni unos ni otros, requieren mayores apuntes descriptivos para el lector y si bien no integran los bestiarios, ambos tipos pueden considerarse como seres monstruosos, en vistas a su desproporción, por exceso o por defecto.

12. Se trata del tópico del león reverente: "Muchos cavalleros fueron a ver qué farían los leones cuando lo viesen [a Palmerín], porque avía en el corral bien quinze e los más d'ellos coronados. Palmerín yva sin ningún miedo. El leonero abrió la puerta, que aún no les avía dado de comer. Palmerín entró dentro e cerró la puerta tras sí y estuvo quedo por ver qué farían los leones. $\mathrm{E}$ sabed que todos los leones coronados que allí estavan no se curaron d'él porque conocieron ser de sangre real, mas avía entr'ellos tres leones pardos que eran muy crueles a maravilla e como lo vieron levantáronse muy apriessa e viniéronse para él. El leonero le dio bozes que se saliesse; él no lo quiso fazer e echó el manto en el braço e sacó su 'spada e fírió al primero que a él se llegó, de tal ferida que no se menó más, mas antes cayó muerto. Los otros dos rompiéronle todo el manto con las uñas mas él los paró tales en poca de ora que poco le pudieron empecer. Él, desque los ovo muerto, vínose a la puerta e abrióla e salió fuera. [...] Devía de venir de alto linaje pues los leones coronados no le avían querido fazer mal" (PO, LXXIX: 168).

13. "La huerta era muy espessa de árboles que davan de sí grande olor e en ella avía caños de agua muy sotilmente labrados e avía muchas aves que muy dulcemente cantavan, tanto que ellos sintieron en sus coraçones grande alegría e quisieran allí estar mucho tiempo, si lo pudieran fazer. E sobre todas las aves que cantavan se conocía a la que criava en el árbol, que era cosa maravillosa de oýrla [...]. Palmerín muy sutilmente se subió amochado por él [Trineo] hasta que llegó a él e muy passo la tomó [al ave]; e quando ella se sentió presa dio tres bozes, las más dolorosas e espantosas del mundo, las quales todos los que en el castillo estavan las oyeron e fueron desencantados e tornados en sus propios juicios. Palmerín fue muy ledo quando la tovo en sus manos e falagávala mucho, mas no aprovechava nada. E luego Palmerín cojó las flores del árbol que estavan muy frescas e finchió la copa d'ellas. E quando esto fue fecho el día era claro e vieron a su voluntad la huerta [...] e ansí como ellos salieron, la niebla se quitó [...] Yo [Muça Belín] quiero que llevéys con vos para vuestra tierra el ave que sacastes del castillo. porque vos acordéys de mí cada vez que la vierdes; e de aquí adelante ella no avrá menester de comer mas bevirá [...] tanto quanto vos biviérdes e aquel día que los vuestros días serán fenecidos morirá ella. E sabed que tres días antes ella anunciará la vuestra muerte dando aquellas tres bozes que dio quando la prendistes, e luego vos entenderéys, quando la oyerdes, que la vuestra fin es llegada, e otras señas fará que agora no vos digo, que vos las veréys entonces. E este ave faréys vos poner, quando fuerdes en la vuestra gran ciudad de Constantinopla, en el gran palacio en una alcándara, e sabed que no entrerá cavallero en el palacio, si contra vos alguna trayción quisiere fazer o pensar, qu'el ave no lo demuestre faziendo gran ruydo con las alas, mostrando gran tristeza; e ansimismo quando os uvieren de venir algunas nuevas de que os pesa, fará lo mesmo; e con los cavalleros leales mostrará grande alegría e ansimismo denunciará las buenas nuevas quando vos vinieren. E quando ovierdes de fazer hueste para yr contra algunos que vos farán enojo, ella vos monstrará si vos conviene de fazello o no. E d'esta manera vendrán vuestros fechos en gran cumplimiento e vos en grande alteza" (PO, CXXXIII-CXXXI: 294-299).

14. No es vano recordar que la imagen de la Carta XV del Tarot representa al Diablo en su carácter precisamente andrógino, con uñas filosas que se asimilan a garras, un par de alas y, claro, también cuernos, todos ellos rasgos que pueden aplicarse al basilisco, a fin de reforzar la idea del Anticristo que postulamos. 


\section{RESÚMENES}

La notable influencia del Fisiólogo durante la Edad Media y los siglos posteriores ha hecho de esta obra un pilar para la concepción de lo monstruoso. La sistematización de los monstruos tradicionales y de los animales, considerados virtuosos o pecadores, de acuerdo con su apariencia y sus hábitos biológicos, ha servido como base discursiva e iconográfica para la resemantización del mundo zoológico y teratológico posterior. En este artículo, analizaremos la imagen del basilisco en el Palmerín de Olivia (Salamanca, Juan de Porras, 1511), a la luz del bestiario tradicional.

The remarkable influence of the Physiologus during Middle Age and during subsequent centuries has made this work a pillar of the conception of monsters. The systematization of traditional monsters and animals, considered virtuous or sinful, according to their appearance and biological habits has served as a discursive and iconographic basis for the resemantization of the later zoological and teratological world. In this article, we analyze the image of the basilisk in the Palmerín de Olivia (Salamanca, Juan de Porras, 1511) in the light of the traditional bestiary.

L'influence remarquable du Physiologus au Moyen Âge et aux siècles suivants a fait de cet ouvrage un socle de la conception du monstrueux. La systématisation des monstres et des animaux traditionnels, considérés comme vertueux ou pécheurs, selon leur apparence et leurs habitudes biologiques, a servi ensuite de base discursive et iconographique à la resémantisation du monde zoologique et tératologique. Dans cet article, nous analysons l'image du basilic dans le Palmerín de Olivia (Salamanque, Juan de Porras, 1511), à la lumière du bestiaire traditionnel.

\section{ÍNDICE}

Mots-clés: Physiologus, bestiaires, monstre, basilic, Palmerín de Olivia

Palabras claves: Fisiólogo, bestiarios, monstruo, basilisco, Palmerín de Olivia

Keywords: Physiologus, Bestiaries, Monster, Basilisk, Palmerín de Olivia

\section{AUTOR}

\section{LUCÍA ORSANIC}

Lucía Orsanic (Buenos Aires, Argentina, 1983) es Doctora en Letras por la Universidad Católica Argentina, donde se desempeñó como docente e investigadora con Dedicación Especial, en las categorías Junior y Senior, para el Departamento de Letras, entre 2009-2017. Posee un Máster en Estudios Medievales Hispánicos por la Universidad Autónoma de Madrid. Fue becaria de la Fundación Carolina en la Escuela de Lexicografía Hispánica de la Real Academia Española, en Madrid. Ha participado en congresos nacionales e internacionales, y publicado diversos artículos, particularmente a propósito de la teratología y la zoología literarias, además del libro La mujerserpiente en los libros de caballerías castellanos. Forma y arquetipo de lo monstruoso femenino (Madrid, La Ergástula, 2014). 